Jana Havlíčkováa, Klára Dolejšováa, Michal Tichý, Vladimír Vrkoslav, Blanka Kalinová,

Pavlína Kyjaková* and Robert Hanus*

\title{
$(3 R, 6 E)$-nerolidol, a fertility-related volatile secreted by the queens of higher termites (Termitidae: Syntermitinae)
}

https://doi.org/10.1515/znc-2018-0197

Received November 30, 2018; revised February 7, 2019; accepted March 2, 2019

Abstract: The queens of advanced social insects maintain their reproductive monopoly by using exocrine chemicals. The chemistry of these "queen pheromones" in termites is poorly known. We show that primary queens of four higher termites from the subfamily Syntermitinae (Embiratermes neotenicus, Silvestritermes heyeri, Labiotermes labralis, and Cyrilliotermes angulariceps) emit significant amounts of the sesquiterpene alcohol (E)-nerolidol. It is the dominant analyte in queen body washes; it is present on the surface of eggs, but absent in kings, workers, and soldiers. In E. neotenicus, it is also produced by replacement neotenic queens, in quantities correlated with their fertility. Using newly synthesised $(3 R, 6 E)$-nerolidol, we demonstrate that the queens of this species produce only the $(R)$ enantiomer. It is distributed over the surface of their abdomen, in internal tissues, and in the haemolymph, as well as in the headspace of the queens. Both $(R)$ and $(S)$ enantiomers are perceived by the antennae of E. neotenicus workers. The naturally occurring $(R)$ enantiomer elicited a significantly larger antennal response,

Jana Havličková and Klára Dolejšová: These authors contributed equally to this work.

*Corresponding authors: Pavlína Kyjaková and Robert Hanus, Institute of Organic Chemistry and Biochemistry of the Czech Academy of Sciences, Flemingovo n. 2, 16610, Prague, Czech Republic, E-mail: pavlina.kyjakova@uochb.cas.cz (P. Kyjaková); robert@uochb.cas.cz (R. Hanus). https://orcid.org/0000-0002 7054-1975 (R. Hanus)

Jana Havlíčková, Michal Tichý and Vladimír Vrkoslav: Institute of Organic Chemistry and Biochemistry of the Czech Academy of Sciences, Flemingovo n. 2, 16610, Prague, Czech Republic Klára Dolejšová: Institute of Organic Chemistry and Biochemistry of the Czech Academy of Sciences, Flemingovo n. 2, 16610, Prague, Czech Republic; and Faculty of Science, Charles University in Prague, Prague, Czech Republic

Blanka Kalinová: Institute of Organic Chemistry and Biochemistry of the Czech Academy of Sciences, Flemingovo n. 2, 16610, Prague, Czech Republic; and Faculty of Forestry and Wood Sciences, Czech University of Life Sciences, Prague, Czech Republic but it did not show any behavioural effect. In spite of technical difficulties encountered in long-term experiments with the studied species, $(3 R, 6 E)$-nerolidol remains among eventual candidates for the role in queen fertility signalling.

Keywords: (E)-nerolidol; fertility signalling; higher termites; social insects; Syntermitinae.

Dedicated to: This article is dedicated to the memory of Philippe Cerdan (1959-2018), co-director of HYDRECO laboratory of Petit Saut in French Guiana.

\section{Introduction}

Advanced social insects represent an extreme case of polyphenism, manifested by the presence of dramatically different castes in their colonies. Although arising from the gene pool common to all colony members, individual caste phenotypes differ not only in their reproductive potential, but also in anatomy, behaviour, physiology, and, last but not least, in longevity [1]. This is particularly true for socially advanced termites from the family Termitidae (also called higher termites). Their queens are characterised by high lifelong fecundity, often accompanied by large body size due to the continual growth of their abdomens (physogastry) and an extraordinary lifespan reaching, in some cases, more than a decade [2]. Besides the adaptations directly linked with the longterm high fecundity, the queens must also invest in the maintenance of their reproductive monopoly in the colonies so as to be recognised and treated as queens by other colony members and to prevent their nestmates from reproducing. In spite of the large body of evidence that these "fertility signals" are conveyed by exocrine chemicals secreted by the queens, little is known about their chemical identity [3].

Queen fertility signalling is often proposed to be mediated by the chemical profile of cuticular hydrocarbons (CHCs), protecting the body surface against desiccation. The contact signalling of queen presence and fertility by 
CHCs is well established in social Hymenoptera (ants, bees, wasps) [4, 5], and if confirmed in termites, it would represent a striking example of a convergent evolution of chemical communication in the two unrelated groups. Indeed, in several termite species, the CHC profiles have been shown to be caste specific and differ quantitatively and/or qualitatively between queens (eventually also kings) and sterile colony members $[6,7]$. The $\mathrm{CHC}$ profile was shown to shift towards that of fertile reproductives upon exogenous application of an analogue of juvenile hormone, the major regulator of insect reproductive maturation, to subfertile reproductives of the lower termite Zootermopsis nevadensis (Archotermopsidae) [8]. In another model of lower termites, Cryptotermes secundus (Kalotermitidae), the queen-specific CHC profile has been modified towards that of sterile colony members when a gene encoding for a cytochrome $\mathrm{P} 450$ enzyme, probably involved in $\mathrm{CHC}$ biosynthesis and upregulated in queens, was silenced in the queens. Sterile nestmates then revealed the symptoms of reproductive disinhibition, which suggests that the unaltered queen $\mathrm{CHC}$ profile acts as the "primer pheromone," preventing the nestmates from reproduction [9]. Recently, the role of king and queen "recognition pheromone," directly acting on the behaviour of nestmates, has been assigned to one specific CHC, heneicosane, in another lower termite Reticulitermes flavipes (Rhinotermitidae) [10].

However, the set of candidate molecules for the primer or recognition function in queen fertility signalling is not restricted only to CHCs. In several species from different families, proteins and peptides specific to queens (sometimes also to kings) were identified to be secreted by mature reproductives [11]. While the identity of some of the queen-specific peptides is close to insect antimicrobial peptides [12], their hypothesised function in fertility signalling has not been confirmed.

A crucial discovery in the queen fertility signalling dates back to 2010 when the function of primer pheromone, inhibiting the development of replacement queens in the lower termite Reticulitermes speratus (Rhinotermitidae), was attributed to a blend of two volatiles, butyl butyrate and 2-methylbutan-1-ol [13]. These were identified in the headspace of mature neotenic queens and eggs, and besides their role in suppressing the reproductive potential of nestmates, they were found to be attractive to workers. This dual function of a primer pheromone ensuring the reproductive monopoly of the queen(s) and a recognition pheromone, eliciting attraction and tending behaviour in the nestmates, is complemented by antifungal properties of the volatile blend [14]. Thus, as predicted by the theory of chemical parsimony $[15,16]$, the communication function of the volatiles appears to be derived from the ancestral defensive purpose [16, 17].
Current knowledge of the queen-produced recognition and primer pheromones may thus be seen as controversial, because both non-volatile contact signals (CHCs) and highly volatile small molecules were identified as components of fertility signalling. This apparent ambiguity is sometimes explained by the differences in the social complexity of different groups of termites. In small colonies of basal termites (including the studied models $C$. secundus and $Z$. nevadensis), the contact cues based on CHCs may serve both the recognition function and the primer pheromone function, because the nestmates are in frequent direct contact with the reproductives. By contrast, in populous colonies containing thousands of inhabitants, such as those of $R$. speratus, volatile signals are more suitable to spread the information on the presence of a fertile queen $[3,17]$. Therefore, also in the large nest populations of higher termites, a volatile signal emitted by the queen is likely. Non-contact chemical perception of the queen in higher termites is known and acts, among others, as a behavioural modulator during the construction of the royal chamber [18]. In a single species, Nasutitermes takasagoensis (Termitidae: Nasutitermitinae), a queen-specific volatile has been identified as phenylethanol, but its expected function in fertility signalling could not be confirmed, owing to the difficulties inherent in experimental manipulations with the complex and populous colonies of higher termites [17, 19].

The theoretical predictions of volatile fertility signals and the first observation of queen-specific volatile in higher termites prompted us to perform a systematic survey of volatile exocrine chemicals of queens and other castes in the South American higher termites from the subfamily Syntermitinae. We describe elsewhere the identification and enantiodivergent synthesis of $(5 Z, 9 S)$ tetradec-5-en-9-olide, specific to queens of Silvestritermes minutus (Termitidae: Syntermitinae) [20]. Here, we report on the identification of the sesquiterpene alcohol $(3 R, 6 E)$ nerolidol as a queen-specific compound secreted by mature queens of four species from the subfamily, Embiratermes neotenicus, Silvestritermes heyeri, Labiotermes labralis, and Cyrilliotermes angulariceps.

\section{Materials and methods}

\subsection{Origin of the insects}

Entire colonies of E. neotenicus (Holmgren), S. heyeri (Snyder), L. labralis (Holmgren), and C. angulariceps (Mathews) were collected in the rainforest of French Guiana from September 2014 to April 2018 on nine 
localities along the road to Petit Saut $\left(\mathrm{N}^{\circ} 3^{\prime}-5^{\circ} 7^{\prime}\right.$, W52 $57^{\prime}$ $\left.-53^{\circ} 03^{\prime}\right)$. The colonies of $E$. neotenicus inhabit large polycalic epigeous nests located at the base of trees. Silvestritermes heyeri builds medium-size spherical nests, situated most often 1-2 meters above ground level on tree trunks. Labiotermes labralis builds large ovoid nests on tree trunks. Cyrilliotermes angulariceps colonies are most often located in underground nests. The nests were brought to the research station Hydreco at Petit Saut and their central parts directly dissected for sample preparation or transported alive to Prague and kept intact until sampling on moistened rainforest soil in glass vivaria at $29{ }^{\circ} \mathrm{C}$. The number of sampled colonies of each species and methods of sampling and extraction are listed in Table 1.

\subsection{Sample preparation}

As a basic method of surveying the exocrine volatiles secreted by all available castes and the eggs of all four species, we used solvent body washes, either prepared directly at the field station or from colony fragments in Prague. For solvent extraction, cold-anaesthetised termites were extracted in $10 \mu \mathrm{L}$ of solvent per soldier or worker, $100-400 \mu \mathrm{L}$ per primary queen, $20-100 \mu \mathrm{L}$ per neotenic queen, and $200 \mu \mathrm{L}$ per approximately 100 eggs for $10 \mathrm{~min}$ at room temperature (r.t.). The extracts were then stored at $-20^{\circ} \mathrm{C}$ until analysis.

For detailed analyses using other extraction and sampling techniques, we selected only one species, $E$. neotenicus, because its mature colonies contain multiple neotenic queens (up to almost 300), unlike the remaining three species, which have only a single primary queen in their colonies [21]. Fragments of seven different E. neotenicus colonies were kept alive in the laboratory in Prague. We analysed the headspace emissions of volatiles of neotenic queens, primary kings, soldiers, workers, nymphs, and eggs using solid phase microextraction (SPME). One to five living neotenic queens, one king, 5-10 workers, soldiers, or nymphs or approximately 50 eggs of $E$. neotenicus were placed into a 4-mL glass vial. Volatiles were collected on an SPME fiber (PDMS coating, red fiber, $100 \mu \mathrm{m}$; Supelco, St Louis, MO, USA) introduced through a cap septum for 120 min at r.t. To quantify the secretion of selected volatiles to the headspace by the neotenic queens, we used the same SPME setup and sampled the volatiles for $6 \mathrm{~h}$ from one and five neotenic queens (three replicates).

Alternatively, the SPME fiber was used to collect the analytes directly from the body surface of queens and control workers, with the aim of localising the source of detected volatiles. Living individuals were gently held in forceps and rubbed with the fiber 700 times on the dorsal or ventral side of the abdomen. Immediately after sampling, the SPME fiber was thermally desorbed in the gas chromatograph (GC) inlet of the two-dimensional gas chromatograph with time-of-flight mass spectrometric detection (GC $\times \mathrm{GC}-\mathrm{TOFMS})$, operated using the program described below. Two other methods were used to localise the source of the volatiles.

First, we prepared extracts of dissected body tissues of neotenic queens. Three mature physogastric queens from one colony were cold-anaesthetised and individually dissected into four parts, i.e. head + thorax, digestive tube, gonads, and abdominal cavity. Except for the abdominal cavity, the haemolymph from the surface of the dissected tissues was washed out by hexane for $5 \mathrm{~s}$. The tissues were then homogenised in glass vials and extracted in $100 \mu \mathrm{L}$ of hexane for $10 \mathrm{~min}$ under sonication at r.t. Independently, we sampled the haemolymph from dissected queens into

Table 1: Number of samples analysed of each species and caste, extraction, and sampling methods

\begin{tabular}{|c|c|c|c|c|c|c|c|c|c|}
\hline \multirow[t]{2}{*}{ Species } & \multirow[b]{2}{*}{ NeoQ } & \multirow[b]{2}{*}{ PrimQ } & \multirow[b]{2}{*}{ PrimK } & \multirow[b]{2}{*}{ Eggs } & \multirow[b]{2}{*}{ Sold } & \multirow[b]{2}{*}{ Work } & \multirow{2}{*}{$\frac{\text { Caste }}{\text { NeoK }}$} & \multirow[t]{2}{*}{ Extraction method } & \multirow[t]{2}{*}{ Sampling method } \\
\hline & & & & & & & & & \\
\hline \multirow[t]{6}{*}{ E. neotenicus } & 40 & 1 & 3 & 8 & 10 & 20 & 1 & Hexane & Body washes \\
\hline & 3 & & & & & & & Hexane & Extracts of dissected tissues \\
\hline & 3 & & & 1 & & 2 & & Methanol & Body washes \\
\hline & 10 & 1 & 1 & 3 & 3 & 8 & & SPME & Headspace \\
\hline & 3 & & & & & 3 & & SPME & Contact sampling of body surface \\
\hline & 8 & & & & & 8 & & DAPPI & Body surface scanning \\
\hline \multirow[t]{2}{*}{ S. heyeri } & & 4 & 4 & 3 & 3 & 4 & & Hexane & Body washes \\
\hline & & 1 & & 1 & 1 & 1 & & Methanol & Body washes \\
\hline C. angulariceps & & 1 & 1 & 1 & 1 & 1 & & Hexane & Body washes \\
\hline L. labralis & & 3 & 1 & 3 & 3 & 3 & & Hexane & Body washes \\
\hline
\end{tabular}


5- $\mu \mathrm{L}$ glass capillaries, which were then washed out with hexane into glass vials. The liquid fractions of the body part and haemolymph extracts were transferred into new vials and analysed by $\mathrm{GC} \times \mathrm{GC}$-TOFMS.

Second, the body surface of intact cold-anaesthetised queens was scanned using desorption atmospheric pressure photoionisation-mass spectrometry (DAPPI), as described below.

\subsection{Gas chromatography}

The chemical diversity and identity of volatiles were studied by means of gas chromatography coupled with mass spectrometric detection. Preliminary analyses and quantifications were carried out using the gas chromatograph TRACE 1310 (ThermoFisher Scientific, Waltham, MA, USA), equipped with a non-polar Zebron ZB-5MS column $(30 \mathrm{~m} \times 0.25 \mathrm{~mm} \times 0.25 \mu \mathrm{m}$ film; Phenomenex, Torrance, CA, USA) connected to a ThermoFisher Scientific ISQ LT mass-selective detector (70-eV ionisation voltage, source temperature $200{ }^{\circ} \mathrm{C}$, transferline heated to 260 $\left.{ }^{\circ} \mathrm{C}\right)$. The column temperature was held at $50{ }^{\circ} \mathrm{C}$ for $1 \mathrm{~min}$, gradually increased to $320^{\circ} \mathrm{C}$ at $8{ }^{\circ} \mathrm{C} / \mathrm{min}$ and then held at $320^{\circ} \mathrm{C}$ for $20 \mathrm{~min}$. Helium was used as carrier gas at a flow $1.2 \mathrm{~mL} / \mathrm{min}$. Split/splitless port was heated to $200^{\circ} \mathrm{C}$, and samples were injected in splitless mode with a purge time of $1 \mathrm{~min}$. Using the same setup, $(3 R, 6 E)$-nerolidol was quantified in dissected body tissues of $E$. neotenicus neotenic queens using peak area comparison with the calibration curve calculated from the peak areas of a set of serial dilutions of the synthetic compound.

Detailed analyses were performed using a $\mathrm{GC} \times \mathrm{GC}$ TOFMS (Pegasus 3D; Leco, St. Joseph, MI, USA), equipped with a combination of non-polar ZB-5MS (30 m, internal diameter $0.25 \mathrm{~mm}, 0.25-\mu \mathrm{m}$ film thickness, Phenomenex, Torrance, CA, USA) and medium polarity RTX-50 (1.5 m, internal diameter $0.1 \mathrm{~mm}, 0.1-\mu \mathrm{m}$ film thickness, Restek, Bellefonte, PA, USA) columns. In both cases, the temperature program was $50{ }^{\circ} \mathrm{C}(1 \mathrm{~min})$ to $320^{\circ} \mathrm{C}(20 \mathrm{~min})$ at $8{ }^{\circ} \mathrm{C} /$ min. The secondary column of GC $\times$ GC-TOFMS was set $10^{\circ} \mathrm{C}$ higher. For analytes of our interest, Kovats retention index (KI) was calculated using the retention times of $n$-alkanes, co-injected with selected samples [22]. This setup was also used for the quantification of $(3 R, 6 E)$-nerolidol secretion to the headspace of $E$. neotenicus neotenic queens by comparing the peak area of the natural compound after $6 \mathrm{~h}$ of sampling of the queens, with the calibration curve constructed from the peak areas corresponding to the synthetic standard, introduced in two quantities (50 and $500 \mathrm{ng}$ ) and sampled for 3, 4, and $6 \mathrm{~h}$ (three replicates).
Chiral analyses were carried out using gas chromatography with flame-ionisation detector on a column (30 m, internal diameter $0.25 \mathrm{~mm}, 0.25-\mu \mathrm{m}$ film thickness) equipped with a chiral permethylated $\beta$-cyclodextrin stationary phase (HP-CHIRAL-20B; J\&W Scientific, Folsom, CA, USA), enabling separation of chiral compounds. The gas chromatograph (HP-6850; Agilent, Santa Clara, CA, USA) inlet was heated to $200{ }^{\circ} \mathrm{C}$, flame-ionisation detector to $220^{\circ} \mathrm{C}$, and hydrogen was used as a carrier gas at $1.5 \mathrm{~mL} / \mathrm{min}$ flow. The temperature program of the oven was $70(1 \mathrm{~min})$ to $120{ }^{\circ} \mathrm{C}$ (0 min) at $1{ }^{\circ} \mathrm{C} / \mathrm{min}$ and then to $200{ }^{\circ} \mathrm{C}(5 \mathrm{~min})$ at $25^{\circ} \mathrm{C} / \mathrm{min}$.

\subsection{Chemicals and solvents}

Methanol for high-performance liquid chromatography was purchased from Fluka (Honeywell Research Chemicals, Charlotte, NC, USA), and trace analysis $n$-hexane from Merck (Darmstadt, Germany). Hexane was distilled prior to use. The analytical standard of $(E)$-nerolidol was purchased from Sigma-Aldrich (Merck) (catalogue no. 18143). We established its enantiomeric composition to be $98 \% S$ versus $2 \% R$. Tosylchloride ( $p$-toluenesulphonyl chloride) was recrystallised from dichloromethane (DCM)/hexane prior to use. All other reagents and solvents for $(3 R, 6 E)$-nerolidol synthesis were purchased from commercial suppliers and used as received.

\subsection{Desorption atmospheric pressure photoionisation-mass spectrometry}

A newly developed setup combining DAPPI with mass spectrometry was used to map the distribution of volatiles emitted by the queens. Cold-anaesthetised mature neotenic queens of $E$. neotenicus were used to detect the diagnostic fragment $\mathrm{m} / z$ 221.1914, representing [M-H] ion of $(3 R, 6 E)$-nerolidol $\left(\mathrm{C}_{15} \mathrm{H}_{25} \mathrm{O}\right.$, theoretical $\mathrm{m} / z$ 221.1911) along the median line of the dorsal and ventral surface of the body. The details of the setup construction and configuration are given by Rejšek et al. [23].

\subsection{Enantiodivergent synthesis of $(3 R, 6 E)$-nerolidol}

All reactions were monitored by thin layer chromatography on Silica gel $60 \mathrm{~F}_{254}$ (Merck) in hexane/ethyl-acetate 3:1 and detected by iodine staining. Retention factors in hexane/ethyl-acetate (3:1) mixture were: farnesol 0.71; epoxyfarnesol 0.29; tosylate 0.64; and nerolidol 0.69 . Nuclear magnetic resonance(NMR) spectra were measured 
on Bruker Avance $400 \mathrm{MHz}$ spectrometer $(400.1 \mathrm{MHz}$ for ${ }^{1} \mathrm{H}$ and $100.6 \mathrm{MHz}$ for ${ }^{13} \mathrm{C}$, Billerica, MA, USA) in $\mathrm{CDCl}_{3}$ (referenced to the residual solvent signal). High-performance flash chromatography was performed with Biotage SP1 apparatus on Biotage $\mathrm{SiO}_{2}$ columns.

$(2 R, 3 R)$-Epoxyfarnesol was prepared according to a slightly modified literature procedure [24]. Solution of diethyl (-)-tartrate $(1.7 \mathrm{~mL}, 9.9 \mathrm{mmol})$ and $\mathrm{Ti}(\mathrm{Oi}-\mathrm{Pr})_{4}$ (2.8 mL, $9.5 \mathrm{mmol})$ in DCM $(50 \mathrm{~mL})$ was cooled to $-50{ }^{\circ} \mathrm{C}$, and $(2 E, 6 E)$-farnesol $(2.0 \mathrm{~g}, 9.0 \mathrm{mmol})$ in DCM $(10 \mathrm{~mL})$ was added, followed by a solution of $t-\mathrm{BuOOH}(5 \mathrm{~mL}, 20 \mathrm{mmol}$, $4 \mathrm{M})$ in DCM $(2 \mathrm{~mL})$. The reaction mixture was stirred for $2 \mathrm{~h}$ at $-50{ }^{\circ} \mathrm{C}$ and then for $4 \mathrm{~h}$ at $0{ }^{\circ} \mathrm{C}$. Solution of $5 \%$ aqueous tartaric acid was added, and the resulting mixture was stirred for another $2 \mathrm{~h}$ at r.t. and extracted with DCM $(3 \times 20 \mathrm{~mL})$. Combined organic layers were washed with brine $(20 \mathrm{~mL})$, dried over anhydrous $\mathrm{MgSO}_{4}$, and solvent was evaporated. Crude oil was dissolved in diethylether $(60 \mathrm{~mL})$, cooled to $0{ }^{\circ} \mathrm{C}$, treated with $1 \mathrm{M} \mathrm{NaOH}(30 \mathrm{~mL})$, and stirred for $30 \mathrm{~min}$ at $0{ }^{\circ} \mathrm{C}$. Aqueous layer was extracted with diethylether $(3 \times 15 \mathrm{~mL})$, collected organic layer was washed with saturated $\mathrm{NH}_{4} \mathrm{Cl}$ and brine and dried over anhydrous sodium sulphate and evaporated. The crude product was purified by high-performance flash chromatography (from $5 \%$ to $10 \%$ of ethyl-acetate in hexane in 2 L) to give desired epoxyfarnesol $(1.3 \mathrm{~g}, 61 \%) .{ }^{1} \mathrm{H}$ NMR (see Supplementary Material, Figure S2) is in agreement with literature [25].

$(3 R, 6 E)$-nerolidol was prepared in analogy to the published synthesis of $(S)$ enantiomer [26]. $(2 R, 3 R)$ Epoxyfarnesol (300 mg, $1.3 \mathrm{mmol}$ ) was dissolved in DCM $(10 \mathrm{~mL})$ and cooled to $0{ }^{\circ} \mathrm{C}$. 4-Dimethylaminopyridine (DMAP) (3 mg, $0.03 \mathrm{mmol}$ ) and anhydrous triethylamine ( $262 \mu \mathrm{L}, 1.9 \mathrm{mmol}$ ) were added followed by the solution of freshly crystallised TsCl (263 mg, $1.4 \mathrm{mmol})$ in DCM (2 mL). The reaction mixture was stirred at $0{ }^{\circ} \mathrm{C}$ for $6 \mathrm{~h}$ and then for another $6 \mathrm{~h}$ at r.t. Water $(10 \mathrm{~mL})$ was added, and the mixture was extracted with DCM $(3 \times 15 \mathrm{~mL})$, dried over $\mathrm{MgSO}_{4}$, and evaporated. Crude material was used directly in the next step. Tellurium powder ( $323 \mathrm{mg}, 2.5 \mathrm{mmol}$ ), rongalite (sodium hydroxymethylsulphinate dihydrate, 1.79 $\mathrm{g}, 15 \mathrm{mmol})$ in aqueous $1 \mathrm{M} \mathrm{NaOH}(25 \mathrm{~mL})$ was heated to 60 ${ }^{\circ} \mathrm{C}$ for $2 \mathrm{~h}$ and cooled to r.t., and solution of crude tosylate in tetrahydrofuran (THF) $(10 \mathrm{~mL})$ was added. The reaction mixture was stirred at r.t. for $4 \mathrm{~h}$ until tosylate disappeared (monitored by thin layer chromatography). The reaction mixture was then bubbled with air for $2 \mathrm{~h}$ to oxidise unreacted telluride ions and filtered through a pad of cellite; the filter aid was washed with diethyl ether $(30 \mathrm{~mL})$, and the filtrate was extracted with diethylether $(3 \times 15 \mathrm{~mL})$. The slightly yellow ether layer was then decolourised with a few drops of hydrogen peroxide, washed with sodium thiosulphate and brine, dried over $\mathrm{MgSO}_{4}$, and evaporated. Crude oil was purified by flash chromatography on silica ( $5 \%$ of ethyl-acetate in hexane) to provide $(3 R, 6 E)$-nerolidol (175 mg, 63\%) as a colourless oil. ${ }^{1} \mathrm{H}$ NMR is in agreement with literature (see Supplementary Material, Figure S3) [27].

\subsection{Electrophysiology}

To test the perception of the queen-produced $(3 R, 6 E)$ nerolidol by the sterile colony members and eventual preference of $(R)$ or $(S)$ enantiomer, we performed a series of electroantennographic (EAG) recordings using the antennae of E. neotenicus workers. The setup and its general configuration are described in our previous studies [28, 29]. Antennae of six different workers were individually exposed to a series of stimulations, each of them consisting of control air and methanol stimulations and serial dilutions of $(3 S, 6 E)$-nerolidol and $(3 R, 6 E)$-nerolidol (10, 100,500 , and $1000 \mathrm{ng}$ in methanol were applied to the carrier paper discs). The data from each series were related to the response to methanol stimulation. Heteroscedasticity inherent to EAG data was reduced by means of logarithmic transformation using the formula $y=\log (10 x)$. The responses to $(3 S, 6 E)$-nerolidol and $(3 R, 6 E)$-nerolidol were compared for each concentration by means of a Student $t$ test, after the initial control of homogeneity of variances using Levene test.

\section{Results}

\subsection{Caste composition in inspected colonies}

As expected from our previous observations [21], all 20 inspected mature colonies of $E$. neotenicus were headed by one primary king and multiple (up to 267) physogastric neotenic queens (Figure 1A). We also collected and sampled several young neotenic queens at different stages of maturity, as judged from their body pigmentation and level of physogastry. Only two colonies, inhabiting very small nests, were headed by one primary king and one primary queen.

In agreements with our expectations, all colonies of S. heyeri (five sampled nests), L. labralis (four sampled nests), and $C$. angulariceps (two sampled nests) contained a single pair of primary reproductives (Figure 1B-D). 

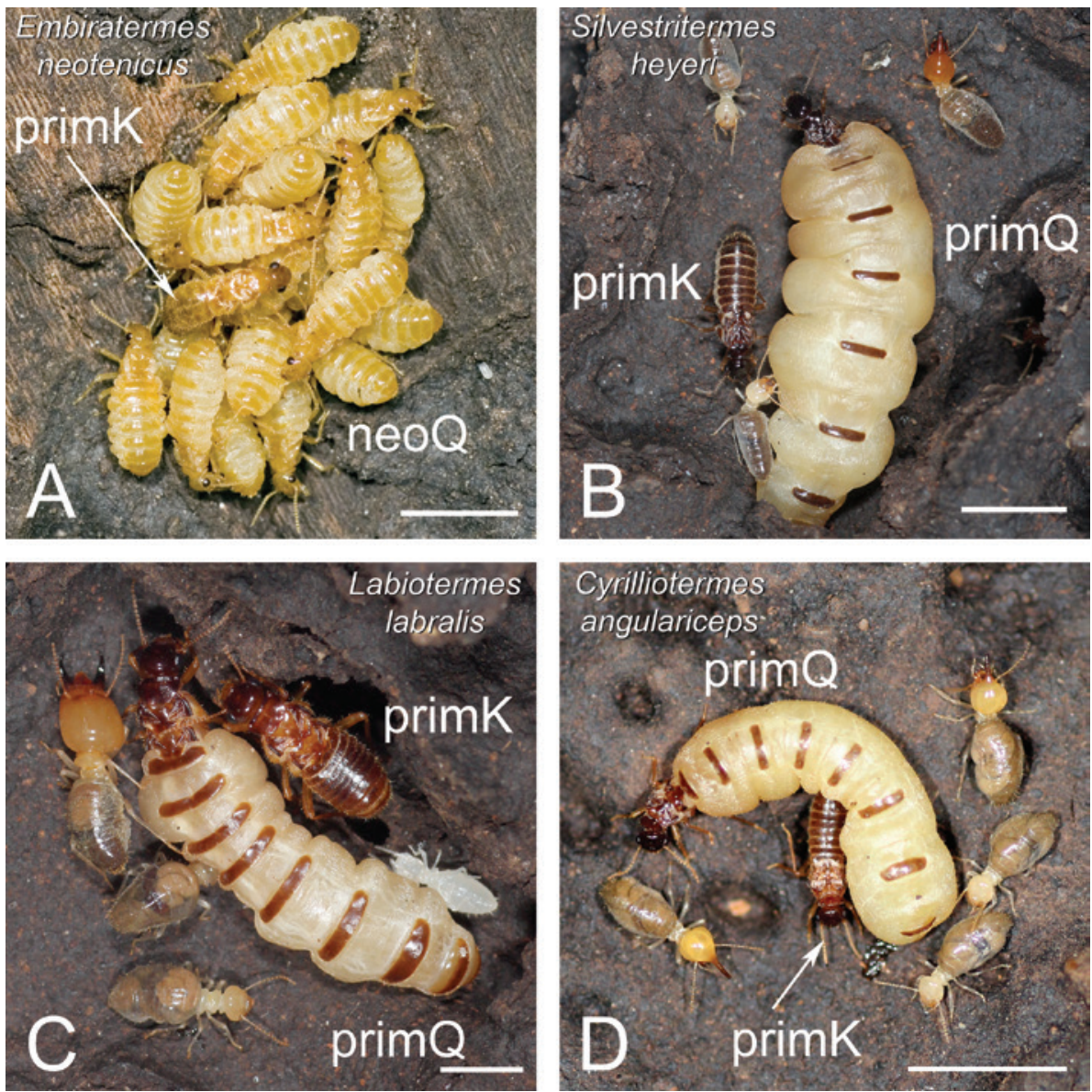

Figure 1: Photographs of reproductives of the four species investigated in this study. E. neotenicus, primary king and neotenic queens (A); S. heyeri, primary king and primary queen (B); L. labralis, primary king and primary queen (C); and C. angulariceps, primary king and primary queen (D). Abbreviations: primK, primary king; primQ, primary queen; neoQ, neotenic queens. Scale bars represent $5 \mathrm{~mm}$.

\subsection{Queen-specific volatile in body washes}

Details of the typical chromatograms of the volatile fraction obtained by GC $\times$ GC-TOFMS analyses of hexane body washes of primary queens, kings, eggs, and workers of the four studied species are depicted in Figure 2. The chemical profiles of the primary queens of all studied colonies of the four species were dominated by one major chromatographic peak with the $\mathrm{KI}=1566$. Based on the retention time and EI mass spectra, the same compound was observed in smaller or trace amounts in the chemical profiles of eggs of the four species. It was also present in large quantities in the body washes of mature physogastric neotenic queens of E. neotenicus in all studied colonies of this species, while it only occurred as a small peak in young, pigmented but non-physogastric neotenic queens, and it was absent in non-pigmented neotenic queens, shortly after their moult from nymphs (Figure 3). This suggests that the production of the volatile is correlated with the sexual maturity of the queens. By contrast, the corresponding peak was absent in all other analysed castes, i.e. primary kings, workers, and soldiers, of all four species.

Besides the volatile fraction, the hexane body washes of different castes in all four species also contained species-specific series of CHCs. We studied in detail the CHC profiles in all castes including reproductives at different stages of sexual maturity in E. neotenicus. The CHCs in this species were identified as consisting of unexpectedly long unbranched or branched, saturated or unsaturated CHCs, having 35-41 carbon atoms. A chromatogram of the GC elution pattern of E. neotenicus CHCs and the queen-specific volatile is shown in Figure S1 (see Supplementary Material). This figure also documents the quantitative dominance of the queen-specific volatile when compared to the CHCs as constitutive part of the epicuticular lipids. Identity, quantitative and qualitative caste specificity of $E$. neotenicus $\mathrm{CHCs}$ and their possible role in contact queen signalling will be presented elsewhere [30]. 

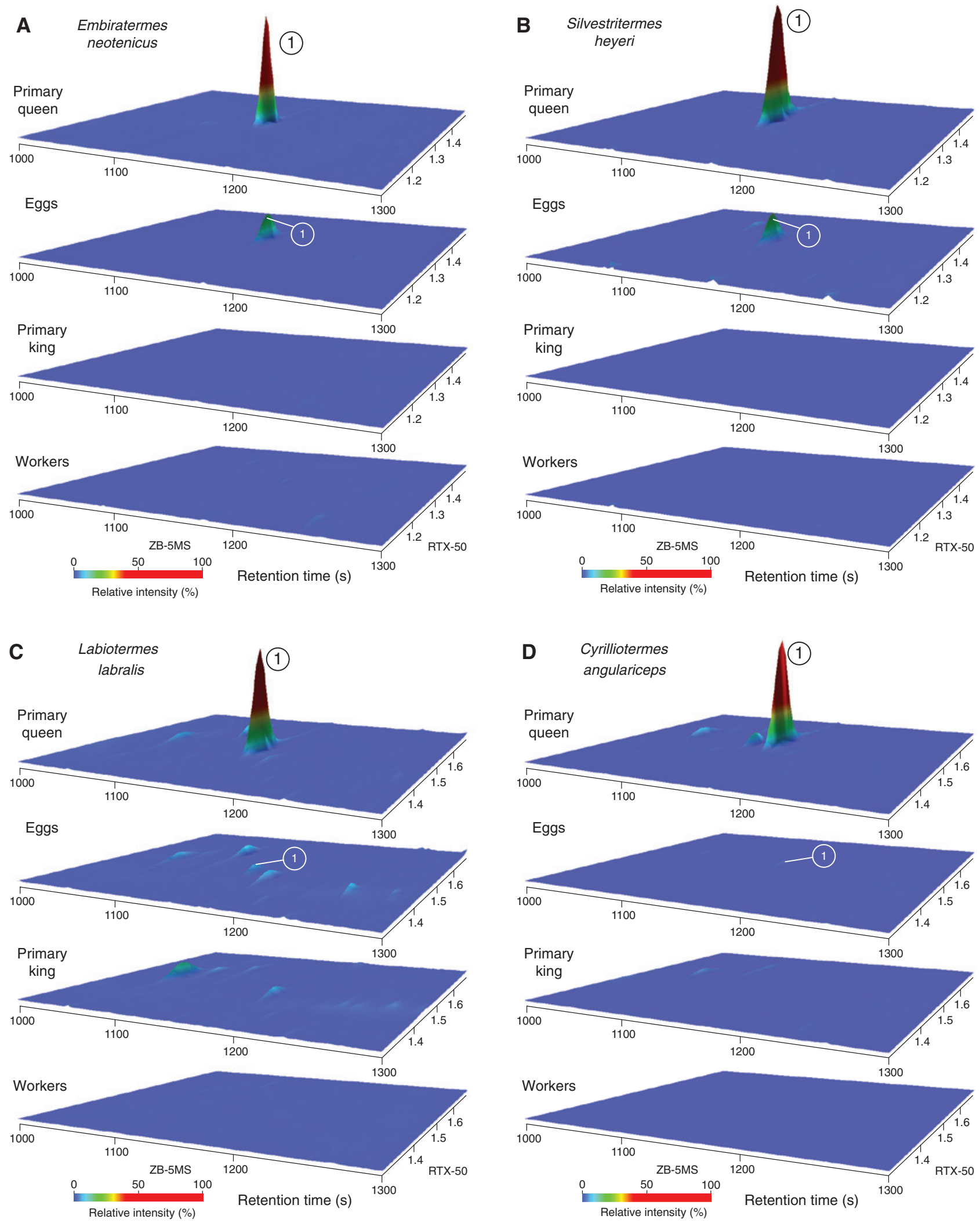

Figure 2: Representative $\mathrm{GC} \times \mathrm{GC}$ chromatograms of body washes of reproductives, eggs, and workers in E. neotenicus (A), S. heyeri (B), L. labralis (C), and C. angulariceps (D). The figure shows the retention area of the volatile fraction as 3D chromatograms, depicting the relative abundance of the queen and egg-specific compound in individual castes. 


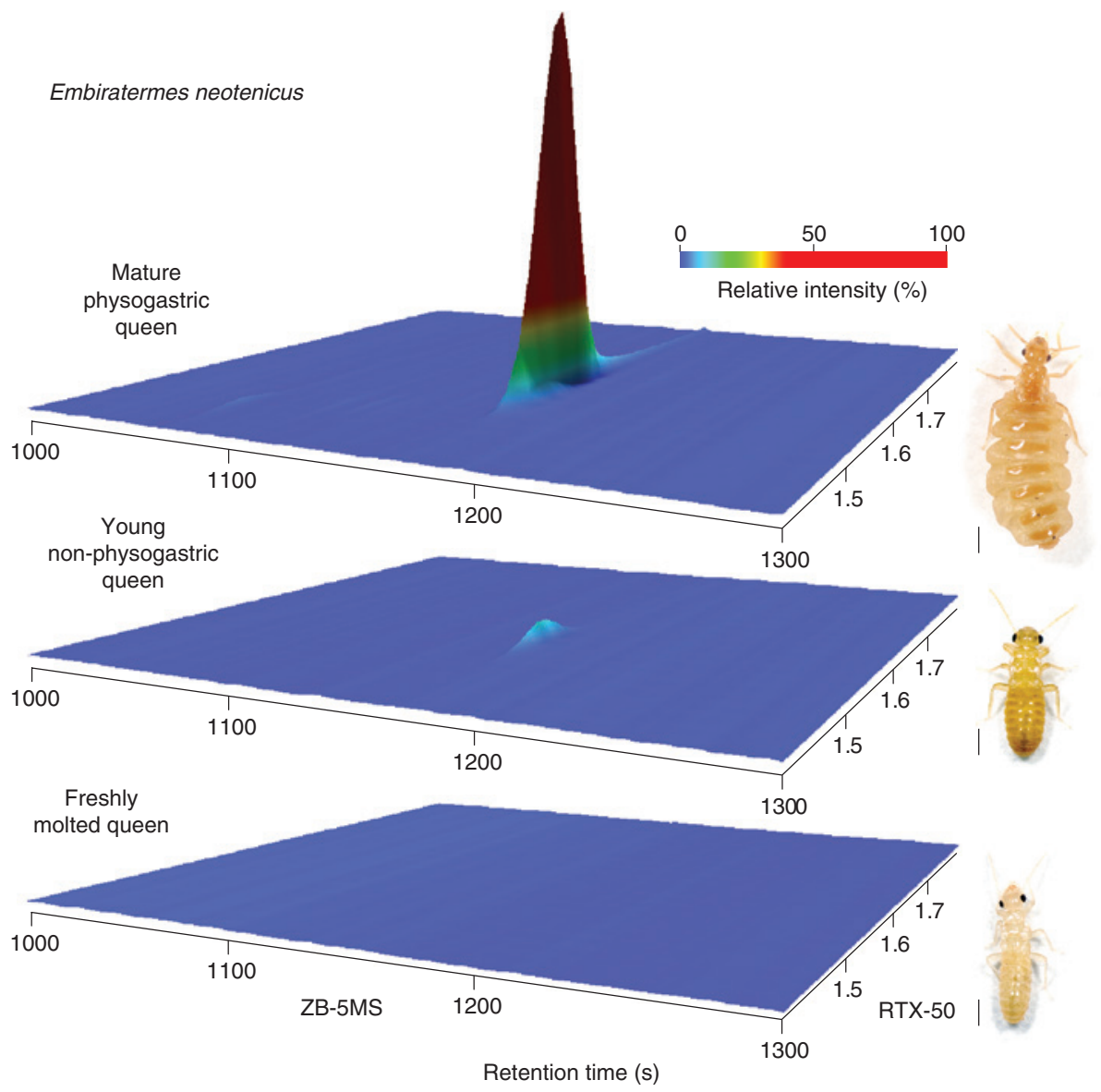

Figure 3: Age- and fertility-dependent production of the queen-specific volatile in $E$. neotenicus neotenic queens. Comparison of GC $\times \mathrm{GC}$ chromatograms of hexane body washes of neotenic females of various stages of fertility, i.e. mature physogastric queen (top), young pigmented but non-physogastric female (middle) and freshly moulted non-pigmented female (bottom). The peak corresponds to ( $3 R, 6 E$ )nerolidol. Scale bar represents $1 \mathrm{~mm}$.

\subsection{Identification of the queen-specific compound}

KI retention index 1566 and EI mass fragmentation (Figure 4) of the queen- and egg-specific compound were matching with those of $(E)$-nerolidol, reported in the literature and libraries of mass spectra (e.g. [31], NIST Mass Spectral Library, NIST\#: 108468). This identification was confirmed by empirical comparison of the retention behaviour and mass fragmentation of the commercially available (E)-nerolidol.

The absolute configuration at the single chiral centre has been established by comparison of the purchased standard $(3 S, 6 E)$-nerolidol with the natural compound from the body washes of E. neotenicus neotenic queens using a chiral GC analysis. We observed a clear shift in the retention times between the two analytes (Figure 5). From the previously reported elution order of the two $(E)$-nerolidol enantiomers on $\beta$-cyclodextrin column
( $R$ followed by $S$ ) (e.g. [32, 33]), we concluded that the natural compound may likely be $(3 R, 6 E)$-nerolidol. To confirm this identification, we decided to prepare the $(3 R, 6 E)$-nerolidol.

\subsection{Enantiodivergent synthesis of $(3 R, 6 E)$-nerolidol}

$(3 R, 6 E)$-nerolidol was prepared in two steps according to slightly modified literature procedures $[24,26]$. The key step of the enantioselective synthesis is asymmetric Sharpless epoxidation of $(2 E, 6 E)$-farnesol by $t$-butyl hydroperoxide in the presence of diethyl (-)-tartrate and titanium(IV) isopropoxide. This reaction was first produced in accordance with the published procedure [24], but due to a low conversion of the starting material (about 50\%), we extended the reaction time from 1 to $8 \mathrm{~h}$ and increased temperature from $-50^{\circ} \mathrm{C}$ to $0^{\circ} \mathrm{C}$. This led to an almost complete 

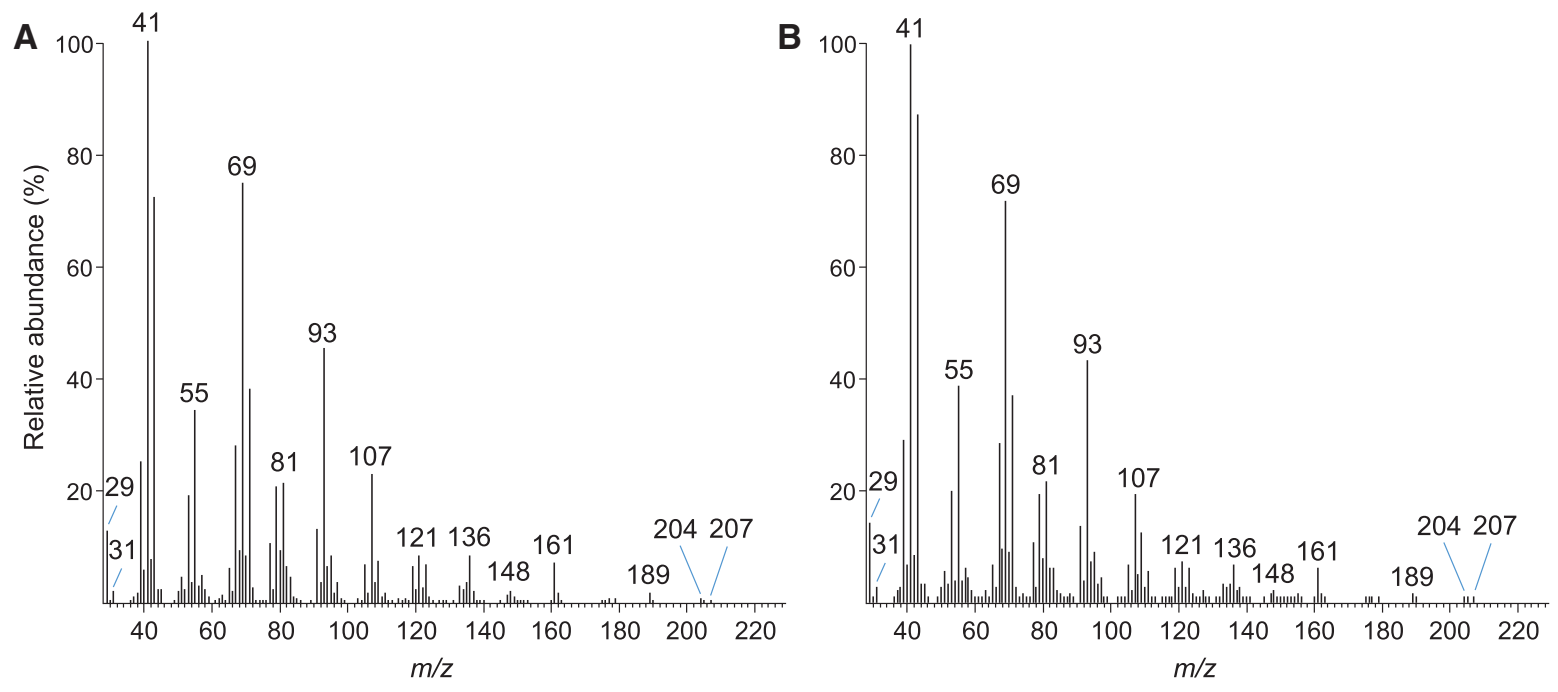

Figure 4: Mass spectrum of the queen-specific compound. Electron ionisation mass spectra of the queen-specific peak detected in the body washes of $E$. neotenicus neotenic queens (A) and of the synthetic $(3 R, 6 E)$-nerolidol (B).

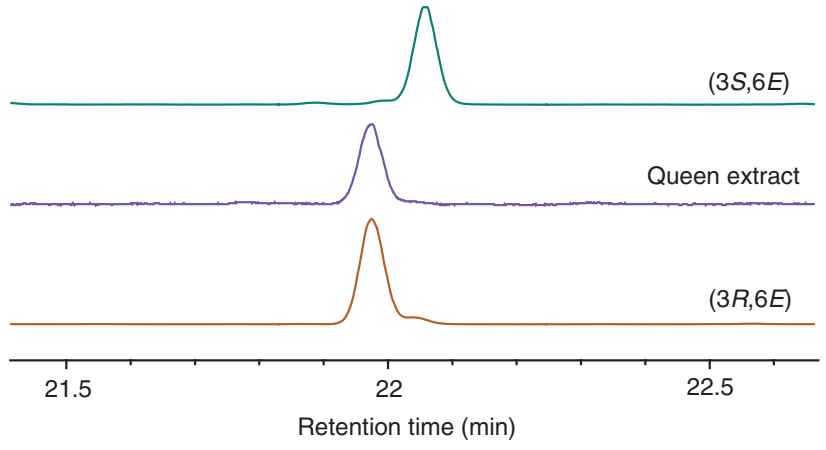

Figure 5: Assignment of the stereochemistry of the studied compound. Chiral GC separation of $(3 S, 6 E)$-nerolidol, $(3 R, 6 E)$ nerolidol and the natural compound from the body washes of E. neotenicus neotenic queen.

transformation and allowed an isolation of a sufficient amount of the desired $(2 R, 3 R)$-epoxyfarnesol. The next step was supposed to be the conversion of epoxyfarnesol to the corresponding triflate and a reduction of the epoxide by activated zinc powder and acetic acid [24]. Because the authors do not mention which of the multiple ways of zinc powder activation [34] they employed, we attempted the activation by TMSCl addition [35] or by stirring with diluted $\mathrm{HCl}$ to remove oxides from the surface [34]. The reaction of triflate with inactivated zinc powder led only to the isolation of epoxyfarnesol, and both experiments with activated zinc provided only the decomposed starting material. Therefore, we changed the strategy and decided to reduce epoxyfarnesol by telluride ion, as this approach was also previously successfully applied in nerolidol synthesis [26]. Epoxyfarnesol was converted to tosylate, and the crude product was directly reduced by telluride ion generated in situ from tellurium and rongalite (sodium hydroxymethylsulphinate). The desired (E)-nerolidol was obtained in 63\% yield. Chiral GC analysis of the isolate revealed that it contained $96 \%$ of $(3 R, 6 E)$-nerolidol and $4 \%$ of the $(S)$ enantiomer (Figure 5). The synthesis is summarised in Scheme 1. Chiral GC comparison showed a perfect match of retention

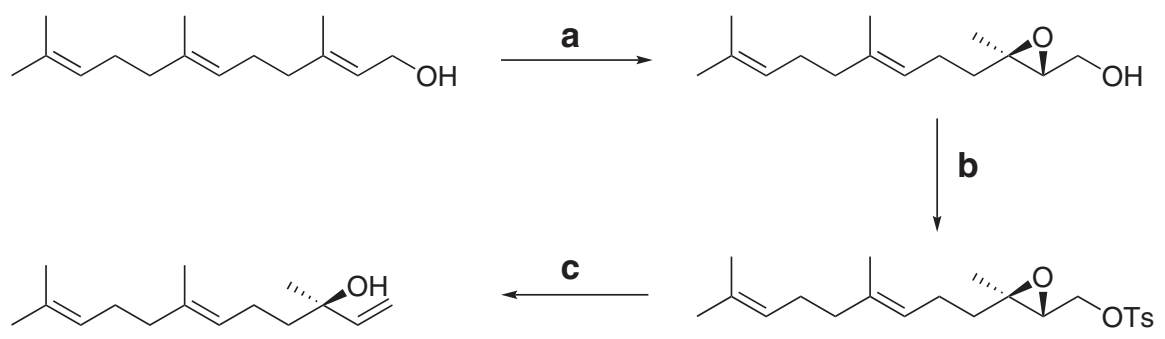

Scheme 1: Synthesis of (3R,6E)-nerolidol: a: $t$-BuOOH (2.2 eq.), diethyl (-)-tartrate (1.1 eq.), Ti(Oi-Pr) ${ }_{4}\left(1.05\right.$ eq.), $\mathrm{DCM},-50{ }^{\circ} \mathrm{C}$ to $0{ }^{\circ} \mathrm{C}, 6 \mathrm{~h}$; b: $\operatorname{TsCl}$ (1.1 eq.), DMAP (0.03 eq.), TEA (1.5 eq.), DCM, $0{ }^{\circ} \mathrm{C}$ to r.t., $18 \mathrm{~h}$; c: Te (2 eq.), rongalite (12 eq.), $1 \mathrm{M} \mathrm{NaOH,} 50^{\circ} \mathrm{C}, 2 \mathrm{~h}$; then tosylate, $\mathrm{THF}$, r.t., 4 h. 
times of the natural compound and the synthetic $(R)$ enantiomer, allowing us to confirm the proposed identity of the natural compound as $(3 R, 6 E)$-nerolidol (Figure 5).

\subsection{Production site of $(3 R, 6 E)$-nerolidol, its distribution, and secretion to the headspace}

Our observations on external anatomy and histological sections of E. neotenicus neotenic queens did not reveal any specific secretory organ responsible for the production of nerolidol. Therefore, we used four different chemical analyses to localise the production and secretion of the compound by E. neotenicus neotenic queens.

First, we analysed the presence of the compound in the headspace of neotenic queens and other castes for comparison. We detected significant quantities of the compound in queen samples and a small amount also in the samples of eggs after 120 min of headspace extraction using SPME, while in the primary king, workers, soldiers, and nymphs, the compound was not detected (Figure 6). In some headspace samples, we detected also a few other queen-specific analytes, namely one to four isomers of the sesquiterpenes $\alpha$ - and $\beta$-farnesene (Figure 6). These, however, were not systematically present in all queen samples. The quantity of $(3 R, 6 E)$-nerolidol secreted by one queen to the headspace during $6 \mathrm{~h}$ of sampling has been estimated to be $132 \pm 17 \mathrm{ng}$.

Second, using the contact SPME sampling of the body surface, we detected comparable quantities of the compound on both ventral and dorsal side of the abdomens of the queens, suggesting that the compound is likely released through epidermis onto the cuticular surface. In control workers, the compound was not detected.

Third, the DAPPI scanning of the body of queens confirmed the relatively homogeneous distribution of the compound over the ventral and dorsal surface of the abdomen and thorax of the queens (Figure 7). We did not observe any dramatic gradient in signal intensity over the abdominal surface, which would signal an eventual production or storage of the compound in a specialised secretory organ on the abdomen.

And fourth, we analysed the dissected body tissues of the queens (head + thorax, digestive tube, gonads, and abdominal cavity). ( $3 R, 6 E)$-nerolidol was detected in all analysed tissues, in quantities of $9.9 \pm 5.8 \mathrm{ng}$ (mean $\pm \mathrm{SD}$, $\mathrm{n}=3$ ) in the head and thorax, $14.3 \pm 6.2 \mathrm{ng}$ in the digestive tube, $38.2 \pm 17.7 \mathrm{ng}$ in the gonads, and $172 \pm 81.5 \mathrm{ng}$ in the abdominal cavity (containing a portion of body

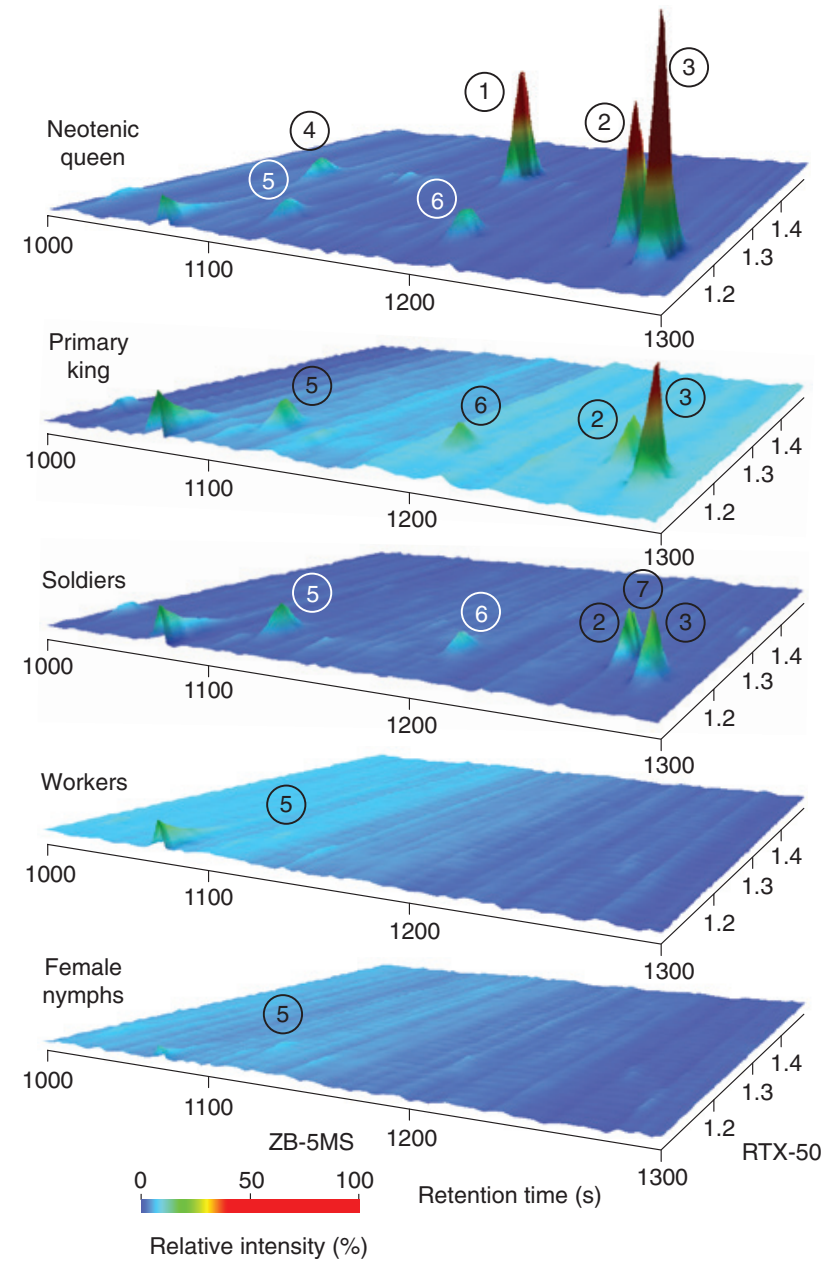

Figure 6: $\mathrm{GC} \times \mathrm{GC}$ chromatograms of headspace samples of E. neotenicus neotenic queens, primary king, soldiers, workers, and female nymphs. Five individuals of each caste (except for a single primary king) were sampled during 120 min using a red PDMS-coated SPME fiber. 1, $(3 R, 6 E)$-nerolidol; 2, heptadecene; 3, heptadecane; 4, $\beta$-farnesene; 5 , pentadecane; 6 , hexadecane; 7 , heptadecadiene.

haemolymph) per one queen $(n=3)$. In the haemolymph, the quantity of the compound was estimated to be $19.3 \pm 7.4 \mathrm{ng} / \mu \mathrm{L}(\mathrm{n}=3)$.

\subsection{Perception of $(3 R, 6 E)$-nerolidol and $(35,6 E)$-nerolidol by workers}

The EAG analyses indicated that both tested enantiomers of $(E)$-nerolidol are perceived by the antennae of $E$. neotenicus workers when compared to control air and solvent stimulations. Along the gradient of increasing tested doses of the two compounds, we observed an increase in the antennal responses of the workers. At the same time, for each tested dose, the response to the $(R)$ 


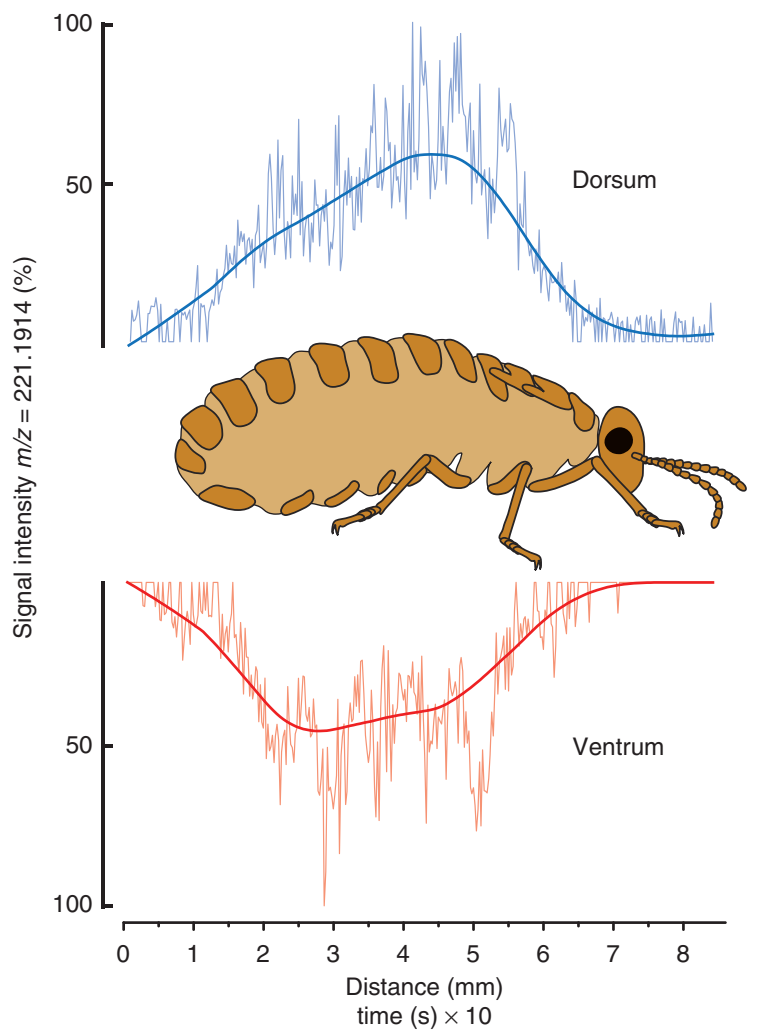

Figure 7: Spatial distribution of $(3 R, 6 E)$-nerolidol on the body surface of queens. DAPPI recordings of the diagnostic ion $\mathrm{m} / \mathrm{z}$ 221.1914 on the dorsal and ventral abdominal cuticular surface of a mature physogastric neotenic queen of $E$. neotenicus. The raw data (thin curve) were converted into moving average data in Statistica 8 and plotted as the thick curve.

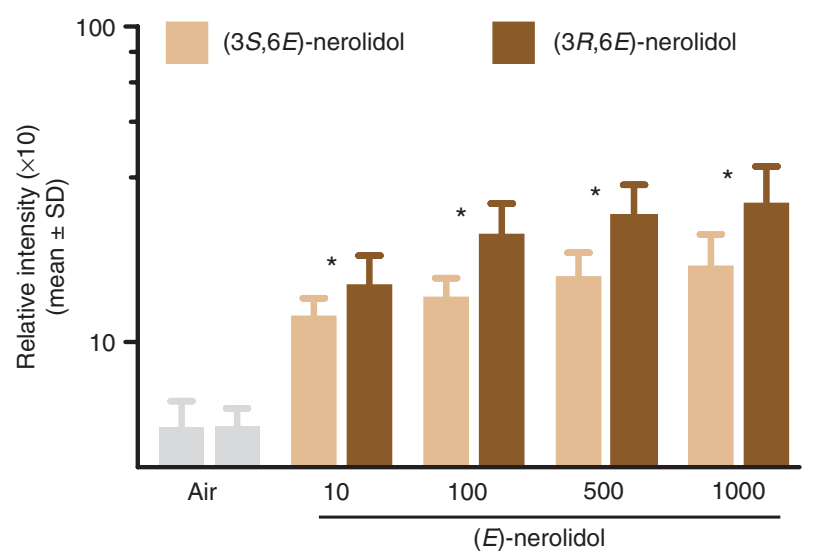

Figure 8: Perception of $(3 R, 6 E)$-nerolidol by workers. Comparison of electroantennographic responses of $E$. neotenicus worker antennae to serial dilutions of $(3 S, 6 E)$-nerolidol and $(3 R, 6 E)$ nerolidol. Each series of stimulations was performed six times with six different workers. The data show the signal intensities relative to the stimulation by control solvent (methanol) in each measurement series on a logarithmic scale. The responses to $R$ and $S$ for each dilution were compared using a Student $t$ test. Significant differences are marked with an asterisk. enantiomer was significantly higher than that to the $(S)$ enantiomer (Figure 8).

\section{Discussion}

In the present article, we show that mature primary queens of higher termites from the neotropical subfamily Syntermitinae (E. neotenicus, S. heyeri, L. labralis, and C. angulariceps) emit large amounts of the sesquiterpene alcohol $(3 R, 6 E)$-nerolidol. This compound represents the dominant analyte in the solvent body washes of queens, analysed by GC-MS, and can be found in smaller amounts also on the surface of eggs laid by these queens. By contrast, the compound has not been detected in the body washes of other castes, i.e. the primary kings, the workers, and the soldiers.

The same compound was also found to be produced in large quantities by the replacement neotenic queens of $E$. neotenicus. Because the colonies of this species contain a harem of many neotenic queens, we were able to perform detailed analyses of the distribution and quantity of $(3 R, 6 E)$-nerolidol using these multiple neotenic females, which would not be possible in species having only a single primary queen in their colonies. We have shown that the queens produce only the $(R)$ enantiomer of nerolidol and confirmed its identity using newly prepared $(3 R, 6 E)$-nerolidol. We observed that the compound is secreted in maximum quantities by mature physogastric neotenic queens, only in small amounts by young non-physogastric queens and that it is absent in neotenic females freshly moulted from nymphs, which shows that its production is linked with the fertility status of the queens. The compound is gradually released to the headspace of the queens in quantities of tens of nanograms per hour. Our observations did not reveal any specific exocrine organ responsible for $(3 R, 6 E)$-nerolidol production. Instead, the compound is distributed homogeneously over the ventral and dorsal surfaces of the queen's abdomen, and it is present also in internal tissues (ovaries, digestive tube). It is also present in the haemolymph of the queens. And finally, we demonstrated that both $(R)$ and $(S)$ enantiomers are perceived by the antennae of $E$. neotenicus workers and that at all doses used the naturally occurring $(R)$ enantiomer elicited a significantly larger response than the $(S)$ enantiomer.

Identification of the sesquiterpene alcohol $(3 R, 6 E)$ nerolidol as a queen-specific volatile in the four studied species from the subfamily Syntermitinae is in line with the expectation that queens of higher termites should 
produce volatiles as long-range signals of their presence to their nestmates [3,17]. The quest for queen-specific volatiles in higher termites was prompted by the description of volatile emissions of queens of the lower termite $R$. speratus. The volatile blend revealed to serve as a multifunctional pheromone, inhibiting the reproduction of nestmates (primer pheromone function) and attracting the workers (recognition function), while also having antifungal properties [13, 14, 17]. Himuro et al. [19] reported phenylethanol as the queen-specific volatile in $N$. takasagoensis from the advanced higher termite subfamily Nasutitermitinae. We observed phenylethanol as a queen-specific analyte in another species from the same subfamily, Constrictotermes cavifrons (unpublished). This suggests that the "queen compounds" may be relatively conserved within individual lineages as is also indicated by the identification of $(3 R, 6 E)$-nerolidol in four different genera of the subfamily Syntermitinae, reported here.

By contrast, we recently described a different queenand egg-specific volatile in another species from this subfamily, S. minutus, i.e. the macrolide $(5 Z, 9 S)$-tetradec5-en-9-olide [20]. The compound is unrelated to $(E)$-nerolidol by its structure and expected biosynthetic origin, the former likely arising through cyclisation of hydroxyacid precursors [36], while the latter being presumably derived from the terpenoid biosynthesis pathway, ubiquitous in insects and responsible, among others, for the synthesis of the sesquiterpenoid juvenile hormone [37]. In other aspects, the occurrence of $(5 Z, 9 S)$-tetradec-5-en-9-olide in S. minutus shows striking similarities with that of $(3 R, 6 E)$ nerolidol in E. neotenicus. Also in S. minutus, the primary queen is replaced early in the colony life cycle by multiple neotenic queens [38], and the queen-specific compound is present in large quantities in both queen types and eggs. The quantity of tetradecenolide released by the queens increases along with their sexual maturation; the compound was the dominant analyte in the headspace of the queens and was detected in large amounts in the internal organs (ovaries, body cavity). We did not observe any direct impact of tetradecenolide on the behaviour of the sterile colony members. Unfortunately, we were not successful in testing the possible long-term effect of the compound on the physiology and development of the nestmates due to difficulties of experimental manipulations with soil-feeding higher termites outside their nests [20], as also observed for other higher termites [17, 19].

The biological function of $(3 R, 6 E)$-nerolidol in the four species studied here remains elusive for the moment. Because the volatile queen pheromone identified in Reticulitermes not only serves as the inhibitor of neotenic development, but is also attractive to workers [13], we first tested the possible behavioural function of the compound. The encouraging EAG data on the perception of both $(E)$-nerolidol enantiomers by the workers and a preference for the native $(R)$ enantiomer prompted us to apply experimental protocols successfully used in our previous studies $[28,39]$ to test the influence of the compound on attraction, trail-following and arresting behaviours of the workers. Yet, we did not observe in these experiments any behavioural effect that may indicate a possible role in queen (and/or egg) recognition and attractiveness, when the compound was tested over the range of biologically relevant doses. The principal candidate role of $(3 R, 6 E)$ nerolidol is to serve as a primer pheromone inhibiting the reproductive potential of nestmates. It is especially plausible in E. neotenicus, in which the primary queen is systematically replaced by neotenic queens. Their development from nymphs and sexual maturation is supposed to be accelerated in the absence of the fertile primary queen as has been observed in the related $S$. minutus with similar breeding system [20,38]. Unfortunately, so far we were not successful in our attempts to design a long-term experiment to test the compound's capacity to suppress or slow down the development of female nymphs into neotenic females, due to the low survival rate of this soil-feeding species in the laboratory. While intact portions of the soil-made nest survive well for several months in the laboratory, their dissection or fragmentation leads to a rapid decline of the population, which hampers the experiments with termite groups, such as those used to test the queen pheromone in the wood-feeding $R$. speratus [13]. These experiments may eventually prove successful when performed with freshly collected colonies in their natural climate.

In spite of these technical difficulties, the possible role of $(3 R, 6 E)$-nerolidol in the signalling as a primer pheromone deserves to be rigorously tested, because it represents an ideal candidate for an "honest signal" of fertility that may act as mid- or long-range signal. It has optimal physicochemical properties and serves as a semiochemical of insects and vertebrates [e.g. 40-43]. At the same time, its biosynthesis likely shares the common precursors with that of the juvenile hormone, which is required for insect female maturation and which is produced in large quantities by fertile termite queens [44]. However, alternative functions of nerolidol should also be considered as the two stereoisomers of this abundant sesquiterpenoid have been documented to exhibit a wide range of biological activities, including antioxidant, antibacterial, and antifungal effects (reviewed in [45]). Some of these properties may be ancestral adaptive functions of the compound. This is the case for the single termite volatile primer pheromone described so far in $R$. speratus, which is supposed to be an 
egg-protection agent, only later co-opted for the secondary function in queen fertility signalling $[3,17]$.

Acknowledgments: This research was funded by the Institute of Organic Chemistry and Biochemistry, AS CR (RVO: 61388963) and the Czech Science Foundation (Funder Id: http://dx.doi.org/10.13039/501100001824, 18-21200S). The authors thank P. Cerdan, R. Vigouroux, and the staff of the Laboratoire Environnement HYDRECO of Petit Saut (EDFCNEH) for logistic support and Jarmila Titzenthalerová for technical assistance with electrophysiological experiments.

\section{References}

1. Wilson EO. The insect societies. Cambridge, MA: The Belknap Press of Harvard University, 1971.

2. Keller L. Queen lifespan and colony characteristics in ants and termites. Insectes Soc 1998;45:235-46.

3. Korb J. Chemical fertility signaling in termites: idiosyncrasies and commonalities in comparison with ants. J Chem Ecol 2018;44:818-26.

4. Van Oystaeyen A, Oliveira RC, Holman L, van Zweden JS, Romero K, $\mathrm{Oi} C A$, et al. Conserved class of queen pheromones stops social insect workers from reproducing. Nature 2014;343:287-90.

5. Liebig J. Hydrocarbon profiles indicate fertility and dominance status in ant, bee, and wasp colonies. In: Blomquist G, Bagnères AG, editors. Insect hydrocarbons. Cambridge: Cambridge University Press, 2010:254.

6. Weil T, Hoffmann K, Kroiss J, Strohm E, Korb J. Scent of a queencuticular hydrocarbons specific for female reproductives in lower termites. Naturwissenschaften 2009;96:315-9.

7. Liebig J, Eliyahu D, Brent CS. Cuticular hydrocarbon profiles indicate reproductive status in the termite Zootermopsis nevadensis. Behav Ecol Sociobiol 2009;63:1799-807.

8. Brent CS, Penick CA, Trobaugh B, Moore D, Liebig J. Induction of a reproductive-specific cuticular hydrocarbon profile by a juvenile hormone analog in the termite Zootermopsis nevadensis. Chemoecology 2016;26:195-203.

9. Hoffmann K, Gowin J, Hartfelder K, Korb J. The scent of royalty: a $\mathrm{P} 450$ gene signals reproductive status in a social insect. Mol Biol Evol 2014;31:2689-96.

10. Funaro CF, Böröczky K, Vargo EL, Schal C. Identification of a queen and king recognition pheromone in the subterranean termite Reticulitermes flavipes. Proc Natl Acad Sci U S A 2018;115:3888-93.

11. Hanus R, Vrkoslav V, Hrdý I, Cvačka J, Šobotník J. Beyond cuticular hydrocarbons: evidence of proteinaceous secretion specific to termite kings and queens. Proc R Soc Lond B Biol Sci 2010;277:995-1002.

12. Monincová L, Březinová J, Ernst UR, Vrkoslav V, Majer P, Hanus R. Characterization and synthesis using regioselective and nonselective folding of cavitin, a novel queen-specific cysteine-rich termicin isolated from queens of the termite Cavitermes tuberosus. J Pept Sci 2016;22:S68.
13. Matsuura K, Himuro C, Yokoi T, Yamamoto Y, Vargo EL, Keller L. Identification of a pheromone regulating caste differentiation in termites. Proc Natl Acad Sci U S A 2010;107:12963-8.

14. Matsuura K, Matsunaga T. Antifungal activity of a termite queen pheromone against egg-mimicking termite ball fungi. Ecol Res 2015;30:93-100.

15. Blum MS. Semiochemical parsimony in the Arthropoda. Annu Rev Entomol 1996;41:353-74.

16. Steiger S, Schmitt T, Schaefer HM. The origin and dynamic evolution of chemical information transfer. Proc R Soc Lond B Biol Sci 2010;278:970-9.

17. Matsuura K. Multifunctional queen pheromone and maintenance of reproductive harmony in termite colonies. J Chem Ecol 2012;38:746-54.

18. Bruinsma OM. An analysis of building behaviour of the termite Macrotermes subhyalinus. Doctoral thesis, Wageningen, Holland: Agricultural University, 1979.

19. Himuro C, Yokoi T, Matsuura K. Queen-specific volatile in a higher termite Nasutitermes takasagoensis (Isoptera: Termitidae). J Insect Physiol 2011;57:962-5.

20. Machara A, Křivánek J, Dolejšová K, Havlíčková J, Bednárová L, Hanus R, et al. Identification and enantiodivergent synthesis of (5Z,9S)-tetradec-5-en-9-olide, a queen-specific volatile of the termite Silvestritermes minutus. J Nat Prod 2018;81:2266-74.

21. Fougeyrollas R, Dolejšová K, Sillam-Dussès D, Roy V, Poteaux $C$, Hanus R, et al. Asexual queen succession in the higher termite Embiratermes neotenicus. Proc R Soc Lond B Biol Sci 2015;282:20150260.

22. Millar J, Haynes K. Methods in chemical ecology: chemical methods. New York: Springer, 1998.

23. Rejšek J, Vrkoslav V, Hanus R, Vaikkinen A, Haapala M, Kauppila TJ, Kostiainen R, Cvačka J. The detection and mapping of the spatial distribution of insect defense compounds by desorption atmospheric pressure photoionization Orbitrap mass spectrometry. Anal Chim Acta 2015;886:91-7.

24. Le Thanh C, Chauhan KR. Simple and short synthesis of trans(R)-nerolidol, a pheromone component of fruit spotting bug. Nat Prod Commun 2014;9:297-8.

25. Marshall JA, Hann RK. A cascade cyclization route to adjacent bistetrahydrofurans from chiral triepoxyfarnesyl bromides. J Org Chem 2008;73:6753-7.

26. Dittmer DC, Discordia RP, Zhang Y, Murphy CK, Kumar A, Pepito AS, et al. A tellurium transposition route to allylic alcohols: overcoming some limitations of the Sharpless-Katsuki asymmetric epoxidation. J Org Chem 1993;58:718-31.

27. Cane DE, Ha H-J, Mcllwaine DB, Pascoe KO. The synthesis of (3R)-nerolidol. Tetrahedron Lett 1990;31:7553-4.

28. Jirošová A, Sillam-Dussès D, Kyjaková P, Kalinová B, Dolejšová K, Jančařík A, et al. Smells like home: chemically mediated cohabitation of two termite species in a single nest. J Chem Ecol 2016;42:1070-81.

29. Sillam-Dussès D, Kalinová B, Jiroš P, Březinová A, Cvačka J, Hanus R, et al. Identification by GC-EAD of the two-component trail-following pheromone of Prorhinotermes simplex (Isoptera, Rhinotermitidae, Prorhinotermitinae). J Insect Physiol 2009;55:751-7.

30. Vaníčková L, Dolejšová K, Vrkoslav V, Kyjaková P, Pompeiano A, Hanus R. The role of cuticular hydrocarbons in queen recognition in the termite Embiratermes neotenicus (Termitidae: Syntermitinae). In preparation. 
31. Adams RP. Identification of essential oil components by gas chromatography/mass spectrometry. Carol Stream, IL: Allured Publishing Corporation, 2007.

32. Schubert V, Dietrich A, Ulrich T, Mosandl A. The stereoisomers of nerolidol: separation, analysis and olfactoric properties. Z Naturforsch C 1992;47:304-7.

33. Arimura G-i, Garms S, Maffei M, Bossi S, Schulze B, Leitner M, et al. Herbivore-induced terpenoid emission in Medicago truncatula: concerted action of jasmonate, ethylene and calcium signaling. Planta 2008;227:453-64.

34. Smith CR. Activated zinc dust. Synlett 2009;9:1522-3.

35. Picotin G, Miginiac P. Activation of zinc by trimethylchlorosilane. An improved procedure for the preparation of beta-hydroxy esters from ethyl bromoacetate and aldehydes or ketones (Reformatsky reaction). J Org Chem 1987;52:4796-8.

36. Schulz S, Hötling S. The use of the lactone motif in chemical communication. Nat Prod Rep 2015;32:1042-66.

37. Noriega FG, Ribeiro JM, Koener JF, Valenzuela JG, Hernandez-Martinez S, Pham VM, et al. Comparative genomics of insect juvenile hormone biosynthesis. Insect Biochem Mol Biol 2006;36:366-74.

38. Fougeyrollas R, Křivánek J, Roy V, Dolejšová K, Frechault S, Roisin $\mathrm{Y}$, et al. Asexual queen succession mediates an accelerated colony life cycle in the termite Silvestritermes minutus. Mol Ecol 2017;26:3295-308.

39. Dolejšová K, Křivánek J, Kalinová B, Hadravová R, Kyjaková P, Hanus R. Sex-pairing pheromones in three sympatric neotropical termite species (Termitidae: Syntermitinae). J Chem Ecol 2018;44:534-46.

40. Goodwin TE, Brown FD, Counts RW, Dowdy NC, Fraley PL, Hughes RA, et al. African elephant sesquiterpenes. II. Identification and synthesis of new derivatives of 2,3-dihydrofarnesol. J Nat Prod 2002;65:1319-22.

41. Khrimian A, Fay HA, Guzman F, Chauhan K, Moore C, Aldrich JR. Pheromone of the banana-spotting bug, Amblypelta lutescens lutescens Distant (Heteroptera: Coreidae): identification, synthesis, and field bioassay. Psyche 2012;2012:8.

42. Aldrich JR, Lusby WR, Kochansky JP. Identification of a new predaceous stink bug pheromone and its attractiveness to the eastern yellowjacket. Experientia 1986;42:583-5.

43. Aldrich JR, Oliver JE, Lusby WR, Kochansky JP, Lockwood JA. Pheromone strains of the Cosmopolitan pest, Nezara viridula (Heteroptera: Pentatomidae). J Exp Zool 1987;244:171-5.

44. Korb J. Chapter four - juvenile hormone: a central regulator of termite caste polyphenism. Adv In Insect Phys 2015;48: 131-61.

45. Chan WK, Tan LT, Chan KG, Lee LH, Goh BH. Nerolidol: a sesquiterpene alcohol with multi-faceted pharmacological and biological activities. Molecules 2016;21:529.

Supplementary Material: The online version of this article offers supplementary material (https://doi.org/10.1515/znc-2018-0197). 